\title{
La metonimia en la configuración gastronómica del quechua de Aurahuá-Chupamarca: un estudio cognitivo
}

Metonymy in the gastronomic configuration of Quechua of AurahuáChupamarca: a cognitive study

\author{
Isabel Gálvez Astorayme \\ Universidad Nacional Mayor de San Marcos, Lima, Perú \\ Contacto: igalveza@unmsm.edu.pe \\ https://orcid.org/0000-0002-1634-3580 \\ Isabel Judith Gálvez Gálvez \\ Universidad Nacional Mayor de San Marcos, Lima, Perú \\ Contacto: igalvezg@unmsm.edu.pe \\ https://orcid.org/0000-0003-2109-7756 \\ Franklin Espinoza Bustamante \\ Universidad Nacional Mayor de San Marcos, Lima, Perú \\ Contacto: franklin.espinoza@unmsm.edu.pe \\ https://orcid.org/0000-0003-2261-3476
}

\section{Resumen}

El presente artículo aborda los aspectos semánticos involucrados en la configuración de la gastronomía de Aurahuá-Chupamarca, distritos de la provincia de Castrovirreyna, región de Huancavelica. Se identifican las motivaciones semántico-culturales que subyacen a las expresiones lingüísticas referidas a las entidades gastronómicas, las cuales se corresponden notoriamente con mecanismos metonímicos. El estudio se sustenta en los principios teóricos y metodológicos de la lingüística cognitiva (Evans y Green, 2006; Ibarretxe-Antuñano y Valenzuela, 2012; Lakoff, 1987; Lakoff y Johnson, 1980; Langacker, 1987, entre otros). Las metonimias evidencian el modo en que los quechuahablantes categorizan las referidas entidades gastronómicas. Así, se describe y explica el modo en que son asociadas las formas lingüísticas a la culinaria quechua.

Palabras clave: Metonimia; Gastronomía quechua; Semántica cognitiva; Lengua y cultura.

\begin{abstract}
This article addresses the semantic aspects involved in the configuration of the gastronomy of Aurahuá-Chupamarca (districts of the province of Castrovirreyna, region of Huancavelica). The semantic-cultural
\end{abstract}


motivations underlying the linguistic expressions referred to gastronomic entities are identified, which correspond notoriously with metonymic mechanisms. The study is based on the theoretical and methodological principles of cognitive linguistics (Lakoff and Johnson, 1980; Lakoff, 1987; Langacker, 1987; Ibarretxe-Antuñano and Valenzuela, 2012; Evans and Green, 2006, among others). The metonymies show how Quechua speakers categorize the indicated gastronomic entities. The way in which linguistic forms are associated with Quechua cuisine is described and explained.

Keywords: Metonymy; Quechua gastronomy; Cognitive Semantics; Language and culture

Recibido: 05.12.19

Aceptado: 05.06.20

\section{Introducción}

Las lenguas son focos dinámicos de innovación léxica. Este nivel se vincula con las diversas actividades que realizan los individuos de un colectivo y se manifiestan en el discurso cotidiano. De esta forma, el quechua presenta un interesante abanico de palabras que, de forma consistente, expresa diversos aspectos de la práctica culinaria. En dichas palabras se evidencian recursos de carácter metonímico que serán descritos. Sostenemos que la constitución de elementos léxicos especializados se crea a partir de la conceptualización de las prácticas gastronómicas, las cuales se experimentan de manera vivencial, de forma que el léxico permite establecer estructuras semánticas.

El presente trabajo aborda el léxico quechua relativo a la gastronomía en los distritos de Aurahuá-Chupamarca, provincia de Castrovirreyna, región Huancavelica, y pone de relieve la manera en que los diferentes términos léxicos referidos a estas prácticas son formados conceptual y semánticamente por el hombre del Ande. En particular, nuestro objetivo reside en describir y explicar de forma sistemática los mecanismos cognitivos de tipo metonímico y su vínculo con los procedimientos culturales que median entre la percepción de la realidad gastronómica del quechuahablante y su conceptualización; ello permite llevar a cabo la significación (o materialización lingüística) del universo gastronómico en la lengua y cultura del quechuahablante.

\section{Antecedentes}

En el Perú, no se registran trabajos de investigación de tipo semántico-cognitivo 
vinculados con la gastronomía quechua. En tal sentido, es poco lo que se sabe sobre la forma en que los recursos semántico-conceptuales (como la metáfora y la metonimia) están involucrados en la conformación del léxico referido a dicha práctica. Sin embargo, entre los estudios semánticos, Calvo (2005) realiza desde esa perspectiva un análisis del léxico de la cocina en lengua quechua desde sus orígenes. El autor recopila los datos de fuentes escritas; además, considera casos de polisemia, sinonimia y derivación de lexemas vinculados con la culinaria quechua. Los significados de los vocablos recopilados comprenden la semántica del tiempo de cocción, el arte y la técnica de la cocina, el conocimiento de los alimentos y su preservación, los procedimientos de la cocina andina, los modos de preparación y la presentación de la comida, la selección de la materia prima, entre otros aspectos relacionados con las diversas actividades que compromete la preparación de alimentos. Todo ello es expresado en lexemas polisémicos. Sobre el particular, desarrollaremos a continuación los aspectos significativos de algunos estudios que, si bien no se vinculan directamente con el objeto de investigación de nuestra pesquisa, realizan un abordaje desde la lengua en uso y la cognición humana.

Lovón (2009) realizó un estudio etnolingüístico y cognitivo en el que se evidencia la correlación entre los platos típicos tupinos y su construcción lexical en lengua jaqaru. Aun cuando no aborda la práctica culinaria en el quechua, el autor describe la forma en que el jaqaruhablante utiliza vocablos relacionados con la gastronomía en cuanto a una motivación sólida mediada por el pensamiento tupino. Así, a partir de su percepción y su conceptualización, las cuales operan como directrices de toda su cosmovisión gastronómica, la denominación de los platos típicos tupinos — data obtenida de su realización de trabajo de campoobedece a los propios requerimientos de la comunidad producto de su percepción experiencial como actores del mundo andino (Lovón, 2009, p. 140).

En el mundo actual, la gastronomía en las ciudades modernas es objeto de atención por la introducción de creaciones culinarias cada vez más sofisticadas, que incluyen la mezcla de ingredientes más insospechados, la exigente elaboración, el cuidado y el refinamiento en la presentación de sus platos. En este contexto, el discurso gastronómico actual de España ha sido abordado por Estornell y Soto 
(2016) con el propósito de realizar un análisis semántico-cognitivo, a partir de un corpus (en lengua castellana) obtenido de cartas y menús de restaurantes de clase alta y media-alta en distintas ciudades españolas. Para las autoras, los mecanismos conceptuales de la metáfora y la metonimia constituyen el eje motor que posibilita la explicación razonada de la creación de nuevas denominaciones culinarias del lugar. Si bien el trabajo de Estornell y Soto asume los presupuestos de la lingüística cognitiva a fin de explicitar cuáles son los patrones conceptuales de naturaleza metafórica y metonímica de la gastronomía en lengua española, ello significa un estudio circunscrito a un área geográfica ajena a la de nuestro objeto de estudio, pues la indagación de las investigadoras se realizó en un ámbito urbano.

Por el contrario, nuestra propuesta se enfoca en el registro lexical de la gastronomía en un área rural de la sierra central del Perú: los distritos de Aurahuá-Chupamarca, provincia de Castrovirreyna, región Huancavelica. Dichas localidades corresponden a zonas de habla quechua, tipificadas lingüísticamente como área fronteriza entre el Quechua I (Q.I) y el Quechua II (Q.II), según la clasificación de Torero $(1964,2001)$. Proponemos que las configuraciones denominativas de la gastronomía quechua de Aurahuá-Chupamarca están fuertemente motivadas por el marco experiencial de los hablantes nativos, y se organizan y dinamizan mediante patrones conceptuales de naturaleza metonímica.

\section{Recursos metonímicos}

El primer trabajo acerca de la metonimia, lejos de los enfoques tradicionales que la consideraban un tropo literario, es el de Lakoff y Johnson (1980). De acuerdo con el análisis que los autores han realizado sobre la metáfora - ello es, un mecanismo conceptual relacionado con la cognición humana-, la metonimia también se asume en los mismos términos; es decir, se trata de “[...] un mecanismo conceptual pero [...] que tiene una base muy distinta" (Evans \& Green, 2006, p. 311). En tal sentido, al ser la metonimia un mecanismo vinculado con la cognición general, dos asunciones son fundamentales para razonar la forma en que aquella hace posible la explicitación de expresiones en el discurso de la gastronomía: el experiencialismo y la corporeización. Ambos términos han sido sostenidos por estudiosos del cognitivismo como Evans y Green (2006), Ibarretxe-Antuñano (2013), Ibarretxe-Antuñano y Valenzuela (2012), entre otros. 
En el marco del experiencialismo, los autores postulan que los mecanismos a través de los cuales el lenguaje articula significados dependen en buena medida del marco de vivencias de los hablantes; en rigor, las experiencias cotidianas motivan fuertemente las expresiones lingüísticas, de manera que es posible detectar los engarces significativos entre ellas. Por otro lado, la corporeización (Johnson, 1992) está vinculada con la experimentación, ya que esta última se realiza a través de nuestro cuerpo. La realidad inmediata es canalizada por nuestros sentidos, de forma tal que nos apropiamos del mundo, lo vivimos a través de las sensaciones; por consiguiente, así se forman los conceptos y estos determinan la verbalización de expresiones lingüísticas.

Al parecer, estas herramientas se asocian con nuestra capacidad para categorizar los objetos del mundo circundante; es decir, la forma en que clasificamos a los animales, las plantas, los objetos, es denominada por Lakoff (1987, p. 6) como categorización, y es de naturaleza inconsciente. Las nociones presentadas (experiencialismo, corporeización y categorización) permitirán razonar la metonimia en el marco de la práctica culinaria como un conjunto de vivencias inmediatas que definen conceptos relativos a la vida íntima de los quechuahablantes. Su significado, con el sustento diario (y ciertas prácticas culturales), estructura un marco conceptual que es funcional para los hablantes de quechua en la zona, y probablemente sea corroborada en cualquier comunidad lingüística en la que se configure el léxico especializado de la gastronomía.

La metonimia se asume entonces como mecanismo conceptual. Sin embargo, entre las diferencias sustanciales con la metáfora, mientras que esta trata de un cruce de dominios (a saber, un elemento relativo a un dominio conceptual se interpreta a través de un elemento que pertenece a otro dominio), la metonimia supone que los elementos relacionados pertenecen al mismo dominio. Así, una metáfora del tipo LAS PERSONAS SON ANIMALES haría posible la expresión Juan es un cerdo (refiriéndose a una persona desagradable), en la cual se evidencian dos dominios: el dominio origen, referido a las personas, y el dominio meta, relativo a los animales. Por otro lado, en una metonimia como EL PRODUCTOR POR EL PRODUCTO (Evans y Green, 2006, pp. 312-313), la relación ocurre dentro de un mismo dominio. Así, en la expresión Lei a Chomsky, el autor reemplaza a su 
obra. Visto de esta forma, siguiendo a Evans y Green (2006, pp. 312-313), las diferencias podrían explicitarse en los siguientes términos:

Figura 1. Metáfora conceptual según Evans y Green (2006)

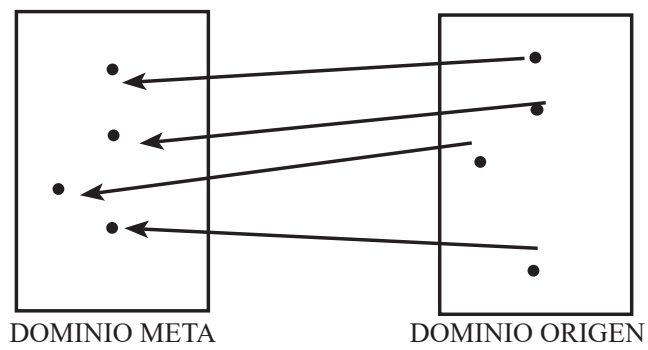

Figura 2. Metonimia conceptual según Evans y Green (2006)

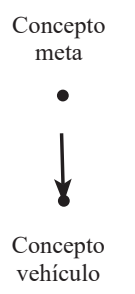

La figura 1 podría representar la metáfora conceptual LAS PERSONAS SON ANIMAles. Como se aprecia, los dominios difieren. Sin embargo, la figura 2 representa un solo dominio en el cual opera la proyección conceptual. Por eso, Barcelona (2012, p. 127) sostiene, citando a Lakoff y Turner (1989), que el recurso metonímico

[...] opera "dentro de un mismo dominio" (a diferencia de la metáfora, de la que se decía que conecta dos dominios no incluidos en un dominio cognitivo común). Pero hay que entender que el dominio común en el que opera la metonimia no es cualquier dominio, sino lo que aquí llamamos un dominio "funcional", es decir, un "marco" o MCI.

De esta forma, son diversos los tipos de metonimia. Entre las descripciones más relevantes, es posible plantear las del tipo LA PARTE POR EL TODO o EL TODO POR LA PARTE (Evans y Green, 2006). Estas permiten la concreción de expresiones como las siguientes: 

a. Quiero una pantalla nueva.
b. Se necesitan dos piernas hábiles para golear.
c. Me chocaron el auto.
d. Perú clasificó al Mundial de Fútbol.

En los casos propuestos en (1) se constatan expresiones metonímicas vinculadas con las metonimias conceptuales previamente expuestas; así, en (1a), el vocablo pantalla hace referencia al televisor; es decir, la parte conceptualizada como más relevante del aparato eléctrico reemplaza a todo el artefacto. En el dato de (1b), la frase nominal dos piernas hábiles hace referencia al deportista; en otros términos, una de las partes del cuerpo del futbolista, la que se conceptualiza como la más importante, sustituye la fisonomía completa. En lo que concierne a la metonimia del TODO POR LA PARTE, en (1c) el auto sustituye a una de sus partes afectadas. Finalmente, la expresión contenida en (1d) destaca al país por encima de un equipo de fútbol. No son los únicos casos de metonimia conceptual, pues también es posible detectar otros como los siguientes (Lakoff \& Johnson, 2017, pp. 70-72):

EL PRODUCTOR POR EL PRODUCTO

Odio leer a Heidegger.

EL OBJETO USADO POR EL USUARIO

Los autobuses están en huelga.

EL CONTROLADOR POR LO CONTROLADO

Un Mercedes me cogió por la retaguardia.

UNA INSTITUCIÓN POR LA GENTE RESPONSABLE

El Senado piensa que el aborto es inmoral

EL LUGAR POR LA INSTITUCIÓN

La Casa Blanca no dice nada.

EL LUGAR POR EL ACONTECIMIENTO

Watergate cambió a nuestros políticos.

En suma, el procedimiento fundamental que se sigue de la metonimia como uno de los mecanismos cognitivos relevantes es el siguiente (Evans y Green, 2006, p. 7): 
Figura 3. Procedimientos cognitivos vinculados con la metonimia conceptual según Evans y Green (2006)

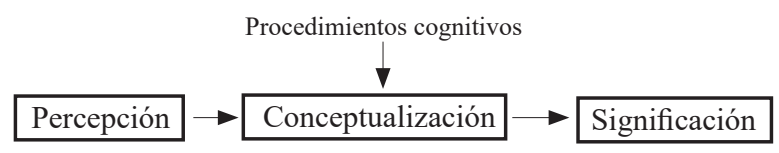

De acuerdo con este marco es que realizaremos, de forma posterior, una descripción sistematizada de los mecanismos metonímicos evidenciados en el léxico gastronómico de Aurahuá-Chupamarca.

\section{Metodología}

Nuestra investigación es de tipo descriptivo-explicativo. Los procedimientos usados para realizar el trabajo de investigación difieren según las diversas fases que constituyen la investigación. Así, la propuesta se inicia con la documentación previa de la bibliografía relativa al tema. Posteriormente, se estructuró un cuestionario a fin de recopilar los datos relevantes referidos al léxico de la gastronomía en la zona de Aurahuá-Chupamarca. Luego, se efectuó el trabajo de transcripción de las grabaciones obtenidas. En suma, los procedimientos realizados fueron los siguientes:

a) Elaboración de un cuestionario para llevar a cabo la entrevista en la zona de Aurahuá-Chupamarca. El cuestionario utilizado para la recolección de datos se estructuró de acuerdo con las diferentes posibilidades semánticas relativas a las metonimias conceptuales en el ámbito gastronómico. Por ello, se requirió de una entrevista abierta que hiciera posible la documentación de pequeñas narraciones en las que el hablante de quechua manifestaba el nombre de las comidas, los ingredientes que utilizaban, su relación con eventos culturales practicados en la zona, entre otros campos potenciales.

b) Observación participante en Aurahuá-Chupamarca. Mediante un rastreo etnográfico previo en el cual se puso en práctica el método de la observación participante se pudo constatar, en la dinámica misma de preparación de comidas, el uso de vocablos quechuas cuyos referentes podían documentarse en una grabación posterior. 
c) Entrevista a quechuahablantes bilingües. Las entrevistas se llevaron a cabo en forma directa, en casos en los que los hablantes de quechua elaboraban las comidas. Sin embargo, esta no fue la única fuente de recolección de datos. También se cruzó la información obtenida con el registro de hablantes bilingües aurahuino-chupamarquinos que residen en Chincha.

d) Transcripción de grabaciones. La recolección de audios permitió que, posteriormente, se realicen transcripciones de las pequeñas narraciones explicitadas por los hablantes nativos de quechua. Luego, se extrajo el conjunto de vocablos relativos a las comidas de la zona altoandina de Aurahuá-Chupamarca, lo cual incluyó el procedimiento de preparación y los ingredientes usados.

A continuación, se efectuará el análisis y la sistematización de los datos recopilados. En esta sección, se organizarán los datos léxicos gastronómicos.

\section{Resultados y discusión}

El mecanismo metonímico fundamental que detectamos en el léxico gastronómico en la zona de estudio podría resumirse al de LA PARTE POR EL TODO. De acuerdo con este procedimiento, uno de los elementos de las comidas se destaca por encima de los demás componentes, de manera que será importante para efectos de la explicación establecer un desglose de todas las posibilidades específicas que están dominadas por esta gran conceptualización metonímica. Así, la estructura de la metonimia LA PARTE POR EL TODO, donde el todo es el producto gastronómico final y la parte alguno de los componentes de los cuales deviene la comida, se subdivide en los siguientes tipos:

(2) El GRANO POR LA COMIDA

EL TUBÉRCULO POR LA COMIDA

LA LEGUMBRE POR LA COMIDA

EL LÍQUIDO POR LA COMIDA

EL ANIMAL POR LA COMIDA

EL PROCESO POR LA COMIDA

EL PROCESO Y EL INGREDIENTE POR LA COMIDA 


\section{EL COLOR POR LA COMIDA}

EL ESPACIO POR LA COMIDA

EL MUERTO POR LA COMIDA Y EL RECINTO POR EL MUERTO

Para una descripción detallada de cada una de las metonimias conceptuales que se desprenden de la metonimia conceptual principal, presentaremos parcelas de datos por cada subtipo, a fin de describir cómo funciona el marco conceptual vinculado con las comidas. Es fundamental para ello incluir la explicación cultural cada vez que sea necesario. Iniciaremos nuestra exposición con la metonimia conceptual en la cual uno de los ingredientes, a saber, el grano, reemplaza o permite la proyección metonímica hacia el concepto de destino relativo al producto culinario.

\subsection{El grano por la comida}

Esta metonimia implica que los hablantes de quechua asumen como marco de referencia al grano para acceder conceptualmente al producto derivado final, a saber, la comida o el plato típico, el cual puede concebirse como el todo (Evans \& Green, 2006, p. 315). Así, en los casos recopilados en los que uno de los ingredientes principales que hacen posible la preparación es un grano, este último pasa a conformar el nombre del plato. Por consiguiente, algunos de los datos obtenidos son los siguientes:
(3) a. Sara lawa
(de sara 'maíz' y lawa 'sopa espesa')
b. Kinwa api de kinwa 'quinua' y api 'mazamorra')
c. Chuchuqa kaldu (de chuchuqa 'maíz cocido y secado', y kaldu 'caldo')

Los datos contenidos (3) son configurados conceptualmente de acuerdo con todo un procedimiento conceptual que se inicia con el marco perceptual, y que involucra la conceptualización y la conformación de la forma lingüística motivada. A continuación, presentamos el esquema para la forma sara lawa. 
Figura 4. Mecanismo metonímico en el nombre de comida sara lawa

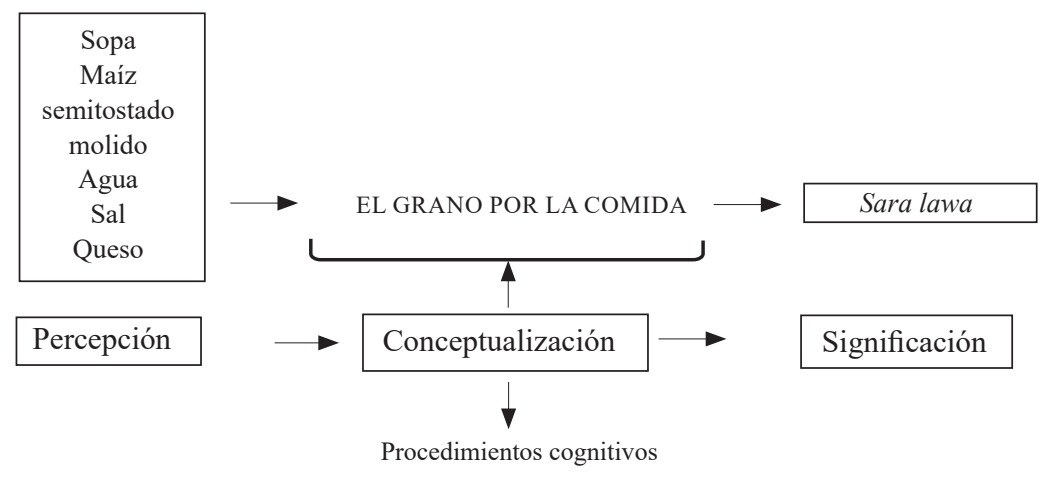

La denominación proviene de dos componentes: sara 'maíz' y lawa 'sopa espesa'. En tal sentido, el vocablo sara es el de mayor relevancia en la construcción. Así, el nombre del grano es el que se proyecta de forma determinante en el nombre gastronómico de este tipo de sopa. Si bien es cierto que se prepara con diversos ingredientes (qarwicha 'harina de maíz', y hierbas aromáticas llamadas chinchi, muña y payku), el que se erige como nuclear es el maíz. Por ello consideramos que el mecanismo metonímico se aplica de la siguiente forma: en la figura 4, se establecen los procedimientos cognitivos que se inician con el marco perceptual de los hablantes de quechua, los cuales experimentan y vivencian los procedimientos para preparar comidas.

De esta forma, los ingredientes de que se compone este plato típico son reconocidos por aquellos. Luego, se conceptualiza la diversidad de componentes mediante la metonimia particular EL GRANO POR LA COMIDA, cuyo relieve se pone de manifiesto en el elemento sara. Notemos que es justamente el maíz el que se erige como el componente más relevante en la expresión. Este procedimiento está orientado a su vez por el marco de vivencias que devienen de la preparación de los platos tradicionales en la zona. Esta aproximación inmediata permite que la expresión sara lawa constituya un signo motivado por la práctica culinaria, en la cual se aplica el procedimiento de forma consistente, pues no es el único caso.

Entre los datos, también se registra la denominación kinwa api y chuchuqa kaldu. En el primero de ellos, es la quinua el elemento medular; en el segundo, lo es el maíz sancochado que posteriormente se seca y se deposita a fin 
de asegurar su preservación. Este maíz seco se muele para preparar la comida denominada chuchuqa kaldu; por ello, es el componente principal. A continuación, presentaremos un esquema de los procedimientos cognitivos involucrados en la denominación de esta última comida, a fin de ilustrar la forma en que se proyecta el mecanismo metonímico.

Figura 5. Mecanismo metonímico en la denominación chuchuqa kaldu

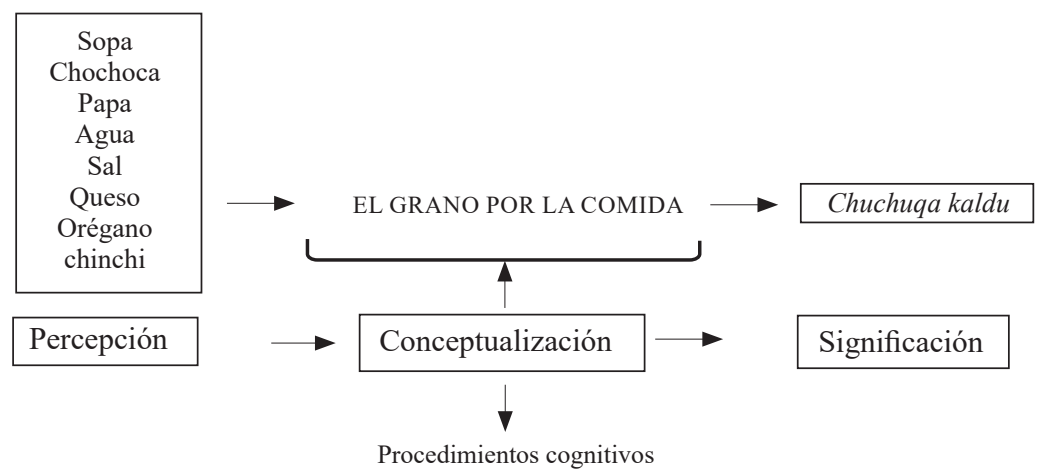

Precisaremos otra de las relaciones que suponen un subtipo de metonimia en la que se explicita la relación de LA PARTE POR EL TODO. Es nuevamente uno de los constituyentes el que se considera el componente fundamental de la denominación del plato típico.

\subsection{El tubérculo por la comida}

Entre los datos, se ha evidenciado que el tubérculo es el que sustenta el nombre de la comida. Así, el vocablo chuñu, además de ulluku, definen el nombre de diversos platos. En estos datos los nombres kaldu y chupi son los elementos genéricos de las construcciones nominales, de manera que es uno de los componentes el que se escoge como medular. Nuevamente, la experimentación derivada de la acción tradicional de preparar la comida genera que se conceptualice de forma jerarquizada a los diversos elementos que se usan en la preparación del producto final. Los datos sobre este tipo de metonimia son los siguientes:
(4) a. Chuñu lawa
(de chuñu 'chuño' y lawa 'sopa espesa')
b. Ulluku chupi
(de ulluku 'olluco' y chupi 'chupe')
c. Chuñu kaldu
(de chuñu 'chuño' y kaldu 'caldo') 
En los datos de (4) se precisan los nombres de comidas. Sustancialmente se trata de sopas cuyos componentes principales son el chuño y el ulluku. De esta manera, la focalización de estos es la que posibilita la subclasificación como producto de la metonimia conceptual. En estas denominaciones, la papa deshidratada, componente fundamental de muchas de las comidas en la región altoandina, es la que define no solo el nombre sino las características de la sopa o el caldo: la consistencia o espesor por ejemplo, la cual se deriva del chuño. En el caso del ulluku chupi 'chupe de olluco', la focalización se centra en el olluco, el tubérculo fundamental de este plato típico. Independientemente de las propiedades sustentadas en la forma de los productos básicos, lo relevante es la jerarquía que se establece entre los componentes de acuerdo con los mecanismos metonímicos. En la figura 6, propuesta a continuación, se grafica la forma en que el hablante de quechua conceptualiza el significado final motivado por la práctica culinaria en la zona estudiada:

Figura 6. Mecanismo metonímico en la denominación ulluku chupi

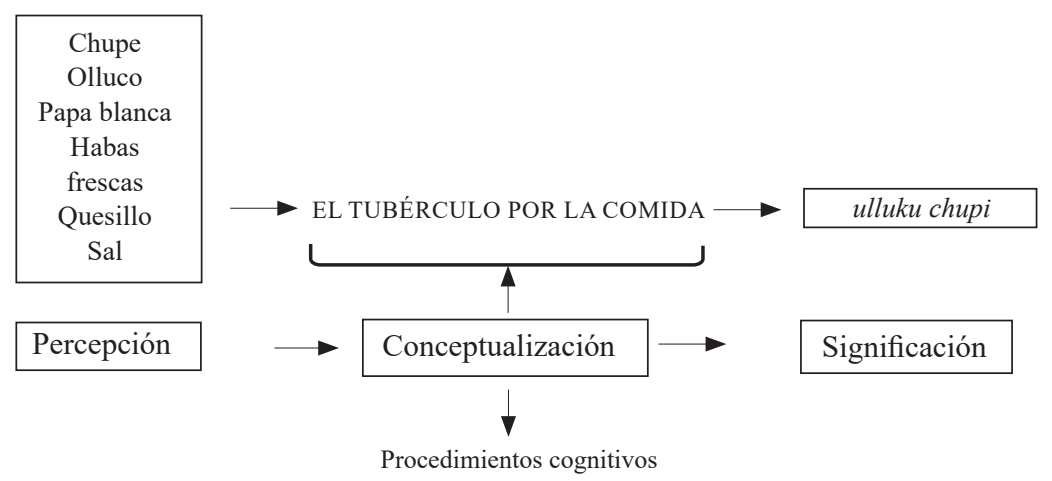

Como ya se indicó, el plato final es una sopa tradicional denominada chupi (o chupe en castellano), del cual se considera fundamental uno de los tantos componentes que lo conforman. En este caso concreto se trata del olluco. Por consiguiente, la denominación final presenta el nombre del tubérculo. El procedimiento metonímico vinculado con el caldo como producto final es el que se define a continuación con el nombre chuñu kaldu. En lo que concierne a esta denominación, el chuño no es simplemente un ingrediente. Se establece 
una prioridad entre los componentes y predomina uno de ellos; a saber, el que determina el plato típico como producto elaborado final.

Figura 7. Mecanismo metonímico en la denominación chuñu kaldu

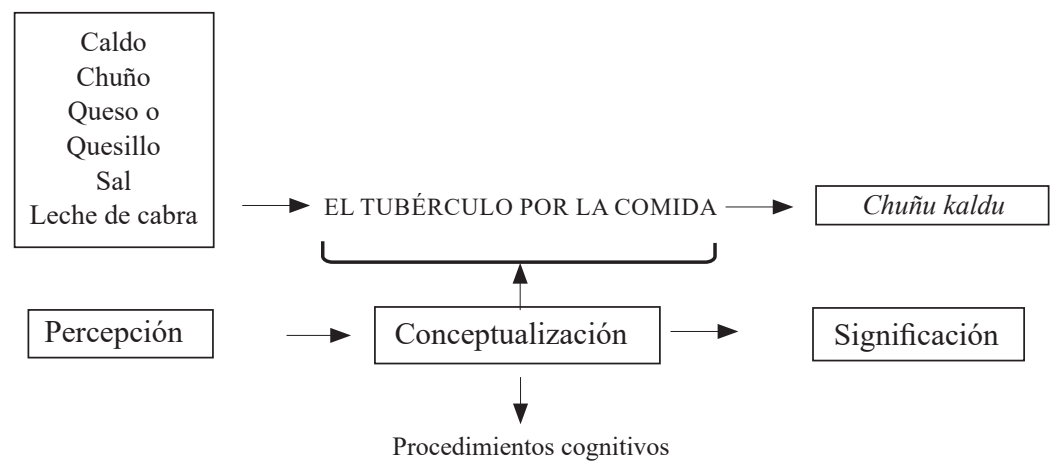

En cuanto al caso anterior, los ingredientes son, además del chuño, el queso, la sal y la leche de cabra. De estos, es la papa deshidratada la que determina el nombre del plato típico. Nuevamente es el tubérculo el que se impone por encima de la comida en tanto producto culinario. En los párrafos siguientes se discutirá el procedimiento metonímico en el cual es la legumbre la que define la denominación.

\subsection{La legumbre por la comida}

De forma consistente, en los casos en que el plato típico está conformado por una legumbre, esta desplaza a los demás ingredientes y define la denominación de la comida tradicional. El nombre, en estos casos, obedece a la metonimia conceptual en la cual es la legumbre la que orienta la denominación final. Presentaremos algunos de los casos en los que se evidencia el mecanismo en cuestión:
(5) a. Abas tiqti
(de abas 'habas' y tiqti 'guiso')
b. Alberha tiqti
(de alberha 'alverja' y tiqti 'guiso')
c. Abas lawa
(de abas 'habas' y lawa 'sopa espesa')

Los datos de (5) son ilustrativos respecto de la forma en que la metonimia, desde el punto de vista de Evans y Green (2006), constituye una ruta de acceso de un dominio específico a un dominio mucho más amplio, el cual puede constituir una matriz. En este caso concreto, el dominio específico de las 
legumbres es la puerta de acceso al mundo culinario, el cual está definido por la experiencia del hombre andino con la labor de preparación de comidas. Esta última es la entidad mayor entonces y a ella se accede mediante la metonimia. Notemos que el marco experiencial es el que determina la relación conceptual, pues son los distintos ingredientes que selecciona quien prepara los alimentos los que orientan la denominación de los platos típicos. Los ingredientes constituyen partes estructurales del dominio de la cocina y, de manera más específica, del dominio de los platos típicos. En la figura 8, se presentará el esquema metonímico LA LEGUMBRE POR LA COMIDA:

Figura 8. Mecanismo metonímico en la denominación abas tiqti

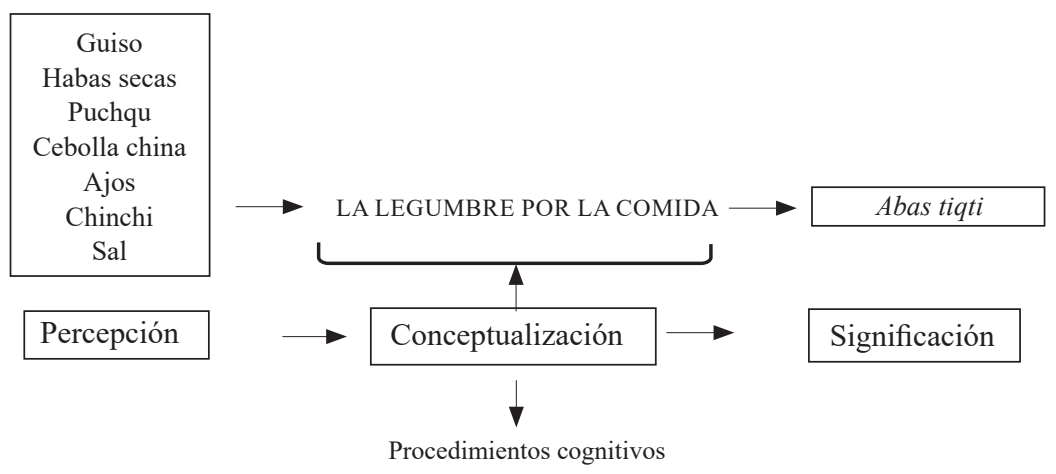

En el caso anterior, el guiso es el producto final cuyo ingrediente principal son las habas. El procedimiento es el mismo para el guiso de arvejas o alwirha tiqti. El mecanismo metonímico determina que sea esta legumbre la que permita acceder al producto. En tal sentido, es importante destacar lo siguiente: la metonimia como ruta de acceso entre dominios posibilita que se acceda también al procedimiento. Por ello, las relaciones con los aspectos culturales son notorias. El quechuahablante no solo es dador o definidor de un simple rótulo o etiqueta. La denominación es una forma de categorizar la experiencia culinaria y las implicancias con el conocimiento del mundo, así como la forma en que se interactúa a través de la comida. Los productos culinarios son parte de un proceso de reconocimiento también de las propiedades particulares y los beneficios de los ingredientes. Incluso, como se verá más adelante, es posible que el producto culinario se relacione con cierta festividad o algún ofrecimiento simbólico. La 
figura 9, presentada a continuación, es un caso más de metonimia cuyo producto final es un guiso:

Figura 9. Mecanismo metonímico en la denominación alwirha tiqti

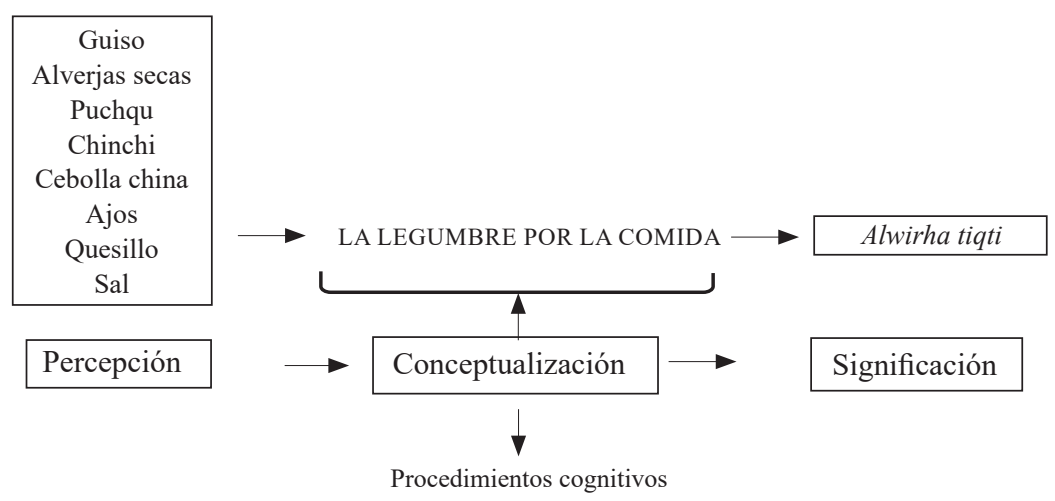

El caso anterior presenta, a diferencia de los datos y las metonimias que lo anteceden, un repertorio de ingredientes más variado. De este, sin embargo, se define a las arvejas como el ingrediente medular. En tal sentido, se configura la metonimia conceptual LA LEGUMBRE POR LA COMIDA en la cual se destaca el ingrediente de un dominio.

\subsection{El líquido por la comida}

Un caso particular de metonimia es aquel en el que la ruta de acceso al producto final es un elemento que usualmente pasa desapercibido en la preparación de alimentos: el agua. Los diversos tipos de sopa, los guisos, entre otros platos, se elaboran con agua. No obstante, en los casos anteriores es otro ingrediente el que orienta la denominación. En cuanto al tema siguiente, el nombre final está determinado por el agua, pues en la denominación yaku chupi 'sopa de agua' es el vocablo yaku el que destaca. Un aspecto importante es que, si bien se trata de un producto culinario, su finalidad no es estrictamente la alimentación. En rigor, este potaje se prepara como tratamiento de afecciones de tipo estomacal. Así, en casos en los que algún individuo presenta los síntomas de un cólico, ingiere esta sopa.

Entre los ingredientes que se usan para prepararla son diversas las plantas cuyas propiedades medicinales destacan; sin embargo, no es una de ellas en particular la que orienta la denominación final. Por ejemplo, se usa el 
paico (Dysphania ambrosioides), el cual permite contrarrestar los efectos de los cólicos; y la muña (Minthostachys mollis), cuyas propiedades para el tratamiento de afecciones estomacales son reconocidas. Además de las plantas medicinales, este caldo de olla se prepara con wakatay (Tagetes minuta) que es una hierba aromática, papa, ajos y sal. Como ya se dijo, no es uno de estos ingredientes el más relevante en rigor, sino es el producto líquido final el que se usa contra los problemas estomacales. Es la razón potencial por la cual es el líquido el que se impone como elemento fundamental; así, al tratarse de un plato que hace las veces de brebaje curativo, el agua define el nombre. Presentamos a continuación, el dato que evidencia el recurso metonímico:

$$
\text { a. Yaku chupi }
$$

(de yaku 'agua' y chupi 'sopa')

En el nombre de esta comida se destaca el vocablo yaku 'agua' con lo cual, para el hablante, nominar supone la consideración de que el líquido elemento es el ingrediente primordial, por las razones planteadas líneas arriba. A continuación, se propondrá, en la figura 10, el mecanismo metonímico comprometido en yaku chupi:

Figura 10. Mecanismo metonímico en la denominación yaku chupi

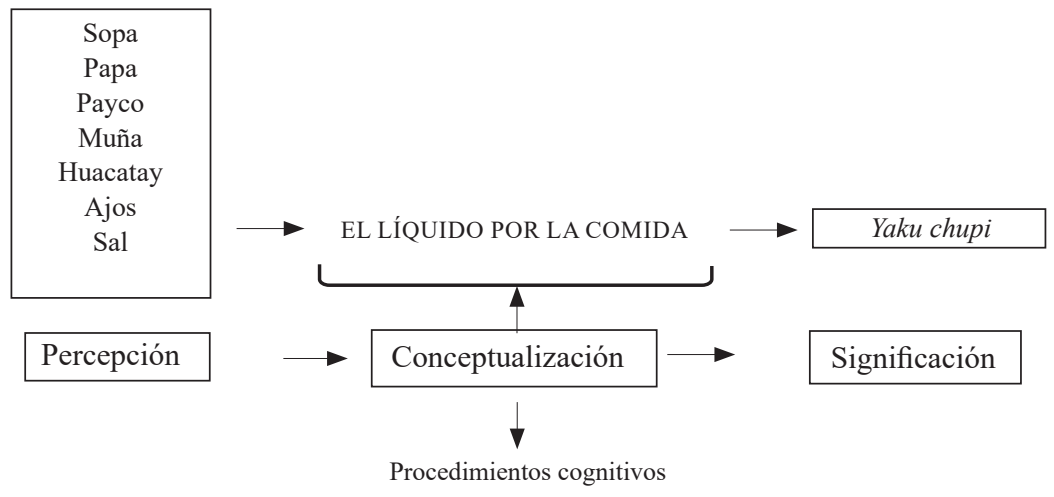

En la figura propuesta, se presentan los ingredientes usados para preparar este plato. Estos son conceptualizados a través de la metonimia, la misma que determina que la denominación de la comida considere al agua como el elemento fundamental. Ello se explica por la propiedad curativa del plato típico. En las líneas siguientes, se abordará la metonimia en la cual es el animal el camino de acceso a la comida para el quechuahablante. 


\subsection{El animal por la comida}

Algunos de los casos documentados incluyen, como parte de los ingredientes usados en la preparación de la comida, animales de diverso tipo. Así, en estos casos la subestructura relativa a los animales es la que resalta como dominio, lo cual deviene en la nominación conceptual del plato típico mediante el nombre del animal como componente fundamental. A continuación, se proponen los siguientes datos:
a. Quwi kaldu
(de quwi 'cuy' y kaldu 'caldo')
b. Wallpa kaldu
(de wallpa 'gallina' y kaldu 'caldo')
c. Uwiha uma kaldu
(de uwiha 'oveja', uma 'cabeza' y kaldu 'caldo')

En los datos propuestos en (7) se configura la metonimia EL ANIMAL POR LA COMIDA. En cuanto a (7a) y (7b), se nomina al plato típico con el vocablo referido al animal. Así, quwi 'cuy' y wallpa 'gallina' son los componentes destacados (o foco), los cuales simultáneamente cumplen con la función diferenciadora de las comidas, mientras que el elemento coincidente es kaldu 'caldo'. No obstante, en el último caso (7c), es la cabeza de la oveja el componente principal del plato típico. En la figura 11, se propone el mecanismo metonímico y sus diferentes fases.

Figura 11. Mecanismo metonímico en la denominación quwi kaldu

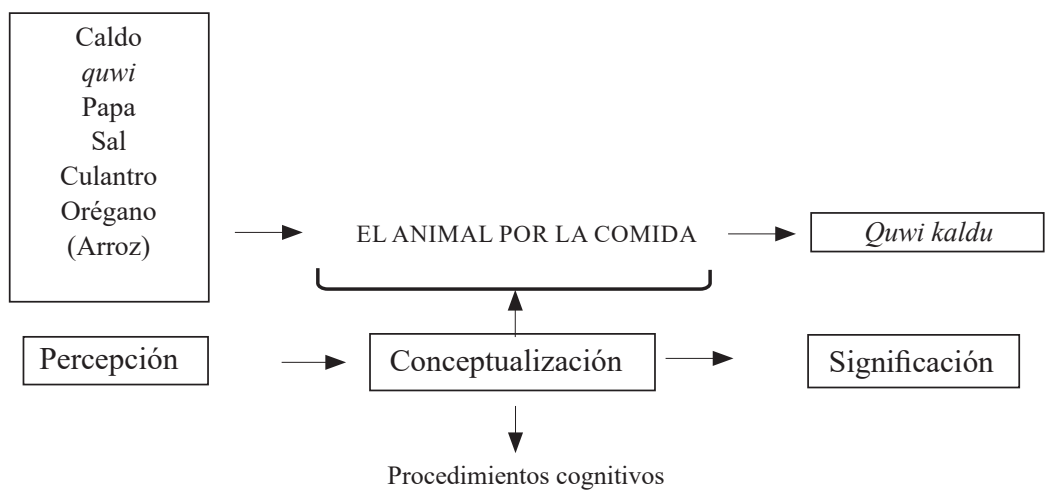


En el caso anterior, se detecta el recurso metonímico mediante el cual un subcomponente animal (el cuy) aparece como el elemento medular de la nominación. Lo anterior supone que el acceso en este caso es el animal. Dicho mecanismo es consistente con la conceptualización del dominio de los ingredientes de tipo animal como acceso a la comida entendida como producto final. En el caso (7c) se evidencia una cadena metonímica en la que LA PARTE DEL ANIMAL POR EL ANIMAL y la que podría formularse como LA PARTE DEL ANIMAL POR LA COMIDA se asocian para precisar el dominio de los ingredientes animales como la ruta de acceso que define el ámbito culinario. Existen otros tipos de metonimias cuya relación con dominios menos concretos es evidente, los cuales serán desarrollados en los apartados siguientes.

\subsection{El proceso por la comida}

Este tipo se vincula con una cadena metonímica en el caso del nombre machka, en el cual la denominación de la comida es el producto final derivado de todo un proceso de elaboración, a saber, la harina de cebada o de maíz. De esta deviene el nombre del plato típico machka. Así, es menester explicar que la harina de maíz o de cebada se produce a través de la fase de tostado de los granos; posteriormente, estos se muelen con batán o molino. Finalmente, los granos triturados son cribados mediante un cernidor, de manera que se obtiene el producto final: la harina. Este alimento es importante en el desayuno del hombre andino de la comunidad de Aurahuá, pues reemplaza al pan y se consume con leche. Se mezclan ambos ingredientes en un plato hasta formar más o menos pequeños montículos de la mezcla (denominado pitu), para ser consumido sin dificultad, pues se corre el riesgo de atorarse. No es el único dato documentado. Algunos de estos se presentan a continuación:
(8)
a. Machka
(de machka 'harina')
b. Sanku
(de sanku 'sango')
c. Qapchi
(de qapchi 'queso machacado con chinchi')

Los datos en (8) corroboran el mecanismo metonímico mediante el cual el producto final de un proceso de elaboración es el que define el nombre del plato típico. En el caso de sanku (8b), se trata de un alimento dulce que se elabora con 
la machka. Se disuelve en una olla la harina de maíz o cebada en agua fría; luego, se pone a fuego lento con azúcar y se añade hojas de anís o manzanilla; asimismo, se le agrega manteca de chancho y se va removiendo hasta que el preparado esté bastante denso, como un budín. En la figura siguiente, se propone el mecanismo conceptual metonímico en particular.

Figura 12. Mecanismo metonímico en la denominación machka

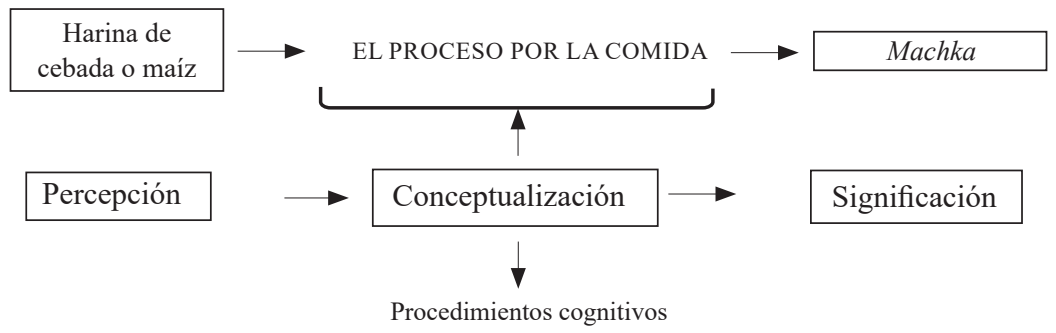

\subsection{El proceso y el ingrediente por la comida}

La forma en que ambos componentes se asocian en una cadena metonímica para nominar al plato típico determina que tanto el proceso de cocción a vapor o pasiy se configure como elemento medular del nombre chuñu pasi, junto con uno de los ingredientes, a saber, el chuñu. En tal caso, la motivación reside tanto en el proceso como en el ingrediente, de manera que la denominación exige la presencia de ambos componentes léxicos: el relativo al proceso y el correspondiente al ingrediente. La configuración metonímica se propone en la figura siguiente:

Figura 13. Mecanismo metonímico en la denominación chuñu pasi

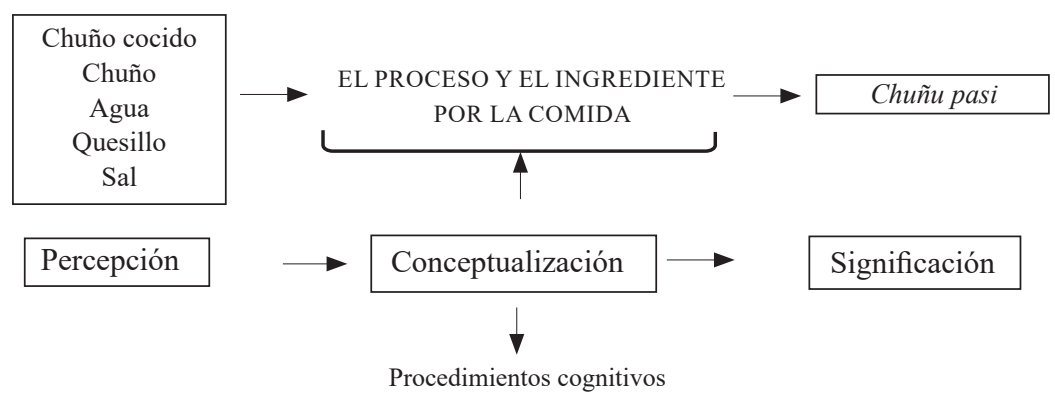




\subsection{El color por la comida}

Es posible detectar que la percepción cromática motiva la configuración de metonimias, en las cuales es el color el que determina el nombre del plato tradicional en quechua. Así, el vocablo pukacha (de puka 'rojo' y -cha 'diminutivo') o rojito, refiere a un picante de harina de maíz blanco con achiote que se prepara adicionalmente con queso y carne. Este nombre proviene de su color rojo característico, el cual se explicita como elemento predominante y categoriza conceptualmente al plato típico. En la figura siguiente, se propone el mecanismo metonímico de este nombre de comida:

Figura 14. Mecanismo metonímico en la nominación pukacha

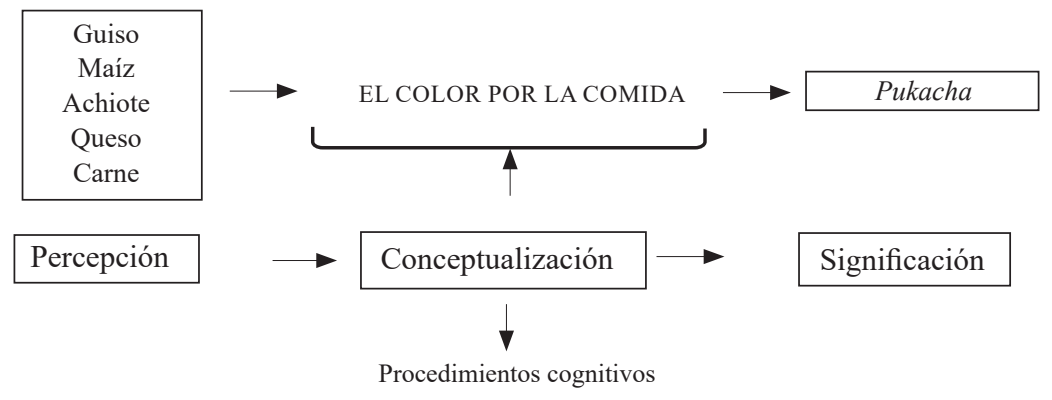

\subsection{El espacio por la comida}

El dominio referido al espacio puede motivar la conceptualización metonímica y producir nombres de comidas. Tal es el caso de la palabra pachamanka (de pacha 'tierra' y manka 'olla'), la cual conecta tanto el mecanismo metafórico como el metonímico. En cuanto a la metáfora, se precisa cavar un hoyo en la tierra y este es categorizado como una olla. A su vez, es el lugar en el cual se prepara este plato típico el que motiva la nominación de la comida, pues en este hoyo se colocan productos como el choclo, la papa, las habas, la oca, el queso, y todo tipo de carnes que previamente son aderezadas con hierbas aromáticas como el chinchi o pachachinchi. Los ingredientes se disponen a través de diversas capas de piedras calientes que sirven para efectos de la cocción. En tal sentido, la entidad espacial pachamanka es el dominio resaltado o el camino de acceso hacia el ámbito de la comida. 
Este caso hace posible la detección de potenciales interacciones entre los mecanismos metafóricos y metonímicos. Lo relacional de ambos mecanismos es predecible en virtud de que estos se caracterizan por constituir "[...] procesos conceptuales que contribuyen a proporcionar estructura al sistema conceptual humano" (Evans y Green, 2006, p. 218). El mecanismo metonímico correspondiente se plantea en la siguiente figura:

Figura 15. Mecanismo metonímico en la nominación Pachamanka

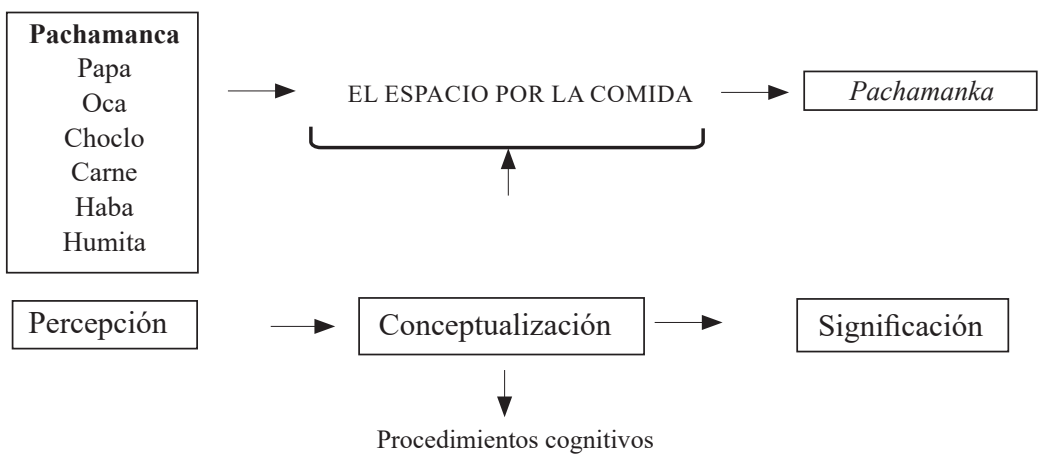

\subsection{El muerto por la comida y el recinto por el muerto}

Un interesante caso de cadena metonímica es el que se propone respecto de la comida denominada tumba mikuy. Esta nominación deviene del préstamo hispano tumba y la palabra quechua mikuy 'comida'. El dato revela aspectos culturales que son importantes discutir. En primer lugar, en el contexto de la muerte de un individuo, pasados cinco días de su deceso, los quechuahablantes acostumbran preparar la comida favorita del muerto. La comida preparada es llevada a la casa del fallecido a fin de establecer una potencial comprobación acerca del retorno de su alma al lugar. Asimismo, existe una actividad que consiste en el esparcimiento de las cenizas en la entrada de la casa del fallecido. Posteriormente, las prendas del difunto son lavadas en el río. Este aspecto es importante en la vida del quechuahablante, pues se cree que el difunto retorna al lugar donde vivió para recoger sus huellas. La conceptualización en este caso se vincula con la experimentación del deceso de un individuo, el cual supone la explicitación de un acto simbólico. Al respecto, Lakoff y Johnson (2017, p. 73) señalan lo siguiente: 
El simbolismo cultural y religioso constituye un caso especial de metonimia [...]. Los sistemas conceptuales de las culturas y las religiones son de naturaleza metafórica. Las metonimias simbólicas son eslabones críticos entre la experiencia cotidiana y los sistemas metafóricos coherentes que caracterizan las religiones y las culturas. Las metonimias simbólicas que se basan en nuestra experiencia física son un medio esencial de comprender los conceptos religiosos y culturales.

En efecto, el simbolismo que entraña esta metonimia conceptual involucra un proceso que supera la simple preparación de una comida, pues la ocurrencia de este evento desencadena una serie de efectos con valor cultural para el hombre andino. En cuanto a la explicitación de la cadena metonímica, la última morada del difunto - a saber, la tumba-, es conceptualizada en reemplazo del muerto. Además, el propio fallecido aparece de forma prominente en el nombre a través del lugar y, en consecuencia, se le considera metonímicamente más relevante que la propia comida.

Figura 16. Mecanismo metonímico en la nominación tumba mikuy

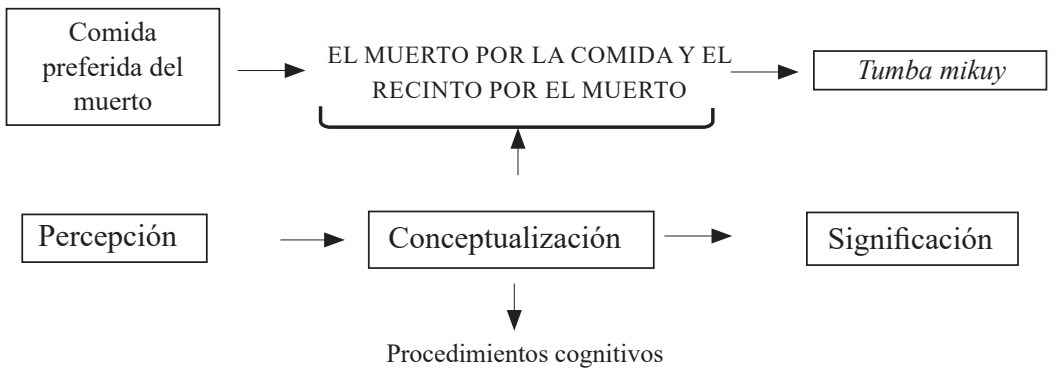

Las metonimias, en consecuencia, han permitido definir la innovación de nominaciones referidas a comidas. Cada uno de estos nombres evidencia una fuerte motivación en la cual la experiencia del quechuahablante es fundamental. Los nombres son moldeados conceptualmente mediante elementos de la realidad que son percibidos y conforman el conocimiento de los hablantes que preparan comidas, ya sea para alimentarse, como remedio ante ciertas afecciones o como acto simbólico frente a la muerte. 


\section{Conclusiones}

a. El proceso de nominación de platos típicos en el quechua ocurre en tres fases definidas. Es decir, en la lengua y la cultura del quechuahablante, resulta medular la consideración de una etapa de percepción, luego una de conceptualización y, finalmente, una de significación (la materialización lingüística). El estadio denominado conceptualización es el que direcciona el proceso de nominación a través de recursos metonímicos.

b. El procedimiento cognitivo fundamental es la metonimia, específicamente la del tipo LA PARTE POR EL TODO. Este procedimiento comprende una tipología más específica, pues involucra una serie de subtipos, tales como EL GRANO POR LA COMIDA, EL TUBÉRCULO POR LA COMIDA, EL LÍQUIDO POR LA COMIDA, EL ANIMAL POR LA COMIDA, EL ESPACIO POR LA COMIDA, EL MUERTO POR LA COMIDA Y EL RECINTO POR EL MUERTO, entre otros.

c. Los quechuahablantes clasifican la gastronomía mediante un mecanismo de categorización conceptual, el cual se define como el conjunto de clasificaciones específicas activadas por la experiencia particular del hombre andino y la corporeización o sensorialidad. Entre los elementos destacan los granos, los tubérculos, las hortalizas, los sabores, los colores, el espacio, etc. Esta clasificación obedece a los mecanismos conceptuales planteados por la lingüística cognitiva.

d. Si bien se han detectado denominaciones de diversas comidas, destacan las sopas espesas, denominadas lawas. Estos platos tradicionales, caracterizados por su espesura consistente, son los más recurrentes; por consiguiente, es posible afirmar que constituyen los elementos prototípicos.

e. Entre las comidas menos prototípicas, cuyos usos son exiguos, sobresalen aquellas que hacen referencia a elementos tales como hierbas, color, animales, legumbres, etc. En resumen, los elementos que se alejan del vocablo prototípico lawa podrían considerarse marginales o, en cuanto al enfoque cognitivo, elementos gastronómicos de naturaleza periférica.

f. Las metonimias explicitan los elementos de la cultura quechua, como se aprecia en la comida ofrendada al muerto. Esta denominación materializa la 
concepción del hombre andino y la necesidad de establecer relaciones con el mundo no corporeizado. Estos permiten comprender las creencias andinas a través de las cadenas metonímicas que se configuran en las denominaciones de comidas.

\section{Agradecimientos}

El presente artículo forma parte de los resultados del proyecto de investigación Aspectos semánticos de la gastronomía quechua de Aurahuá-Chupamarca: un enfoque cognitivo, proyecto que estuvo a cargo de la Dra. Isabel Gálvez Astorayme y que fue desarrollado durante el año 2016 en la Facultad de Letras y Ciencias Humanas de la Universidad Nacional Mayor de San Marcos.

\section{Referencias bibliográficas}

Barcelona, A. (2012). La metonimia conceptual. En I. Ibarretxe-Antuñano y J. Valenzuela (Eds.), Lingüística cognitiva (pp. 123-146). Barcelona: Antrophos Editorial.

Calvo, J. (2005). La cocina peruana. Análisis semántico del léxico de la cocina en lengua quechua. Lima: Universidad de San Martín de Porres.

Estornell, M. \& Soto, A. (2016). La metáfora y la metonimia como procedimientos de creación neológica en el discurso gastronómico actual. Tonos digital: revista de estudios filológicos, 30. http://www.tonosdigital.es/ojs/index. $\mathrm{php} /$ tonos/article/view/1408.

Evans, V. \& Green, M. (2006). Cognitive linguistics: An Introduction. Edimburgo: Edinburgh University Press.

Ibarretxe-Antuñano, I. (2013). La lingüística cognitiva y su lugar en la historia de lingüística. RESLA, 26, 245-266.

Ibarretxe-Antuñano, I. y Valenzuela, J. (2012). Lingüística cognitiva: origen, principios y tendencias. En I. Ibarretxe-Antuñano y J. Valenzuela (Eds.), Lingüistica cognitiva (pp. 13-38). Barcelona: Anthropos Editorial.

Johnson, M. (1992 [1987]). The Body in the Mind. The Bodily Basis of Meaning, Imagination, and Reason. Chicago, Londres: The University of Chicago Press.

Lakoff, G. (1987). Women, Fire, and Dangerous Things. What Categories Reveal 
about the Mind. Chicago: The University of Chicago Press. https://doi. org/10.7208/chicago/9780226471013.001.0001

Lakoff, G. \& Johnson, M. (1980). Metaphors We Live By. Chicago: The University of Chicago Press.

Lakoff, G. \& Johnson, M. (2017). Metáforas de la vida cotidiana. Madrid: Cátedra.

Langacker, R. (1987). Foundations of Cognitive Grammar. Volume I: Theoretical Prerequisites. Palo Alto: Stanford University Press.

Lovón, M. (2009). Hacia una teoría de la complejidad: estudio etnolingüistico y cognitivo de la correlación entre los platos típicos tupinos y su construcción lexical en la lengua jaqaru. (Tesis de Licenciatura en Lingüística). Universidad Nacional Mayor de San Marcos, Facultad de Letras y Ciencias Humanas, Lima, Perú. https://hdl.handle.net/20.500.12672/949

Torero, A. (1964). Los dialectos quechuas. Anales Científicos de la Universidad Agraria, II (4), 446-478.

Torero, A. (2001). Idiomas de los Andes. Lingüística e Historia. Lima: Editorial Horizonte, Instituto Francés de Estudios Andinos. 